\title{
Teaching French to a non-sighted undergraduate: enhancing everyone's learning
}

\author{
Géraldine Enjelvin, University of Northampton
}

\section{Abstract}

In September 2006, during induction week, the French language tutors at the University of Northampton discovered that, John (not his real name), a registered blind student, had enrolled on their post A-level course. Although they had attended a session on accessible documents, the tutors concerned had no previous experience of teaching a non-sighted student. As expressed by Dickinson in 2005, it is 'one thing to go on training about disabilities, [it is another] to have a blind student' (836). This article therefore sets out to illustrate how the French tutors concerned adjusted their (online as well as offline) practices with a view to (1) creating a supportive, enabling, and inclusive teaching/learning (T/L) environment and (2) fostering independent learning (during, and outside of, lessons). Last but not least, this paper also offers suggestions for future, anticipatory adjustments to teaching strategies and (T/L as well as assessment) offline/online materials in line with the lessons learnt from the 2006-2008 academic years.

\section{Keywords: Blind; differentiated T/L; Higher Education institutions (HEI); independent learning; Modern Foreign Languages (MFL); non-sighted students; reasonable adjustments; visually impaired (VI).}

\section{Introduction}

In November 2005, the University of Northampton's French course leader was informed via email that a 17-year-old registered blind student, John (not his real name), had contacted the university with a view to studying French as part of a joint degree. Unfortunately, it is only in September 2006, during induction week, that the French department realized that the student in question had been accepted on their post A-level course. This article therefore intends to illustrate how the French tutors in question adjusted their (online as well as offline) practices so as to (1) create a supportive, enabling, and inclusive teaching/learning (T/L) environment and (2) foster independent learning (during, and outside of, lessons).

'Independent' is defined by The English Collins Dictionary - English Definition \& Thesaurus as 'not reliant on the support of others' (2000); it is synonymous with 'self-reliant'. Within the context of education, different terms are used in the literature to define and describe independent learning. However, a consensus seems to exist: independent learning should not be exclusively associated with learners working entirely on their own. Tutors play a key role in enabling and supporting independent learning. Hence, independent learning is (also) dependent on effective interactions between tutors and learners.

For a broad definition of student autonomy, one might quote Holec, for whom it is 'the ability to take charge of one's learning' (1981, 3). Wenden (1991) has identified several attributes which characterize autonomous language students. However, in this article, only three are significant: (1) learners' insights into their learning styles and their selection, then implementation, of appropriate 
learning strategies; (2) their active approach to the learning activity to be completed and (3) their willingness to take risks (ie to use the target language).

Modern Foreign Languages (MFL) staff who are about to teach a visually impaired (VI) student for the very first time should not ignore Hodgson and Lewin-Jones' recommendation: 'the key here is balance, or maintaining the same language learning experience for all students, adapting where possible but not overcompensating' (2007). The French language tutors endeavoured to heed their advice- which the following sections seek to illustrate.

\section{Recent national legislation}

'Implemented in stages from December 1996, the Disability Discrimination Act [DDA] of 1995 set out new responsibilities for further and higher educational establishments' (Bolt, 2004, 353). In 2001, the Special Educational Needs and Disability Act (SENDA) was introduced and became part four of the DDA. The latter part:

'makes it unlawful for education and training providers and other related services to discriminate against people with disabilities. Essentially, there are three elements to this legislation: an extended definition of disability; an outline of general duties of organisations to promote equality and specific duties for HEIs' (European Agency for Development in Special Needs Education, 2006).

The DDA's keystone is the obligation for education providers to make 'reasonable adjustments' in every single area of student services: (offline as well as online) T/L resources, materials, assessment etc.

\section{The University of Northampton: background information in September 2006 French tutors}

In 2006, the French team felt utterly unprepared, and somewhat anxious, when discovering that they would be teaching a registered blind student. Indeed, although both members of staff had attended a training session on accessible documents, they had never taught a non-sighted student before. As stated by Dickinson in 2005, it is 'one thing to go on training about disabilities, [it is quite another] to have a blind student' (836).

\section{Access Ability Team and figures on students with disabilities}

The members of the Access Ability Team 'promote equal opportunities and facilitate access to enable students who have disabilities, [...] specific learning differences [...], mental health difficulties or medical conditions, to achieve their full potential' (The University of Northampton, 2008 b). Only $0.24 \%$ of the University's full-time undergraduate starters were blind/VI in 2005 2006- whereas dyslexic students accounted for 5.75\% and autistic students for $0.09 \%$; $88.99 \%$ had no known disability (The University of Northampton, 2006). Indeed, nationally, visual impairment is a low incidence disability. The percentage of blind students in British HEIs stood at 0.031 (Carrington-Porter, Patton and Roy, 1994, 42) in June 1991. An analysis of a database of all students in UK HEIs in 1995-1996 revealed that 'students with a visual impairment constituted $0.12 \%$ of all students normally resident in the UK' (Richardson and Roy, 2002, 37)- the percentage of blind students being even lower. In 2004-2005, only 434 UK-domiciled HE blind/partially sighted students graduated (Pumfrey, 2008, 39). In 2007, 696706 undergraduates were in their first year- of whom $1185(0.0017 \%)$ blind/partially sighted (HESA, 2007)- as opposed to 0.0015\% in 
1996-1997 (HESA, 1997). One could therefore concur with Pumfrey who concluded that 'the evidence [...] suggests that the UK is moving towards a more inclusive HE system' (2008, 41)- if only at a considerably slow pace.

Indeed, only one blind/VI student enrolled at the University of Northampton in 2005, against three in 2006 (The University of Northampton, 2008a). It should be noted that John is the very first nonsighted student who has ever enrolled on a MFL course at the University of Northampton.

Consequently, the Access Ability Team members had no previous experience in supporting lecturers teaching MFL to VI/ non-sighted students- hence, understandably, the limited guidance they were initially able to offer to the French tutors.

\section{Non-sighted student concerned}

John has a GCSE in French (grade B) and an A-level in French (grade D). He is an extremely approachable, cooperative, and adaptable young man who is not change-averse. He is an IT literate student who loves France (the country, its culture and its language- he undoubtedly enjoys speaking French). Although he displays a high level of Braille literacy, he prefers using Jaws, a screen reader with synthesized speech. John does not suffer from any additional impairment that may impede his linguistic and academic performance. One should emphasize at this point that the VI pupils "who [...] go on to university represent a highly selective group because they have managed to do so despite their impairment and greater difficulty in accessing written information' (Klinkosz, Sekowski and Brambring, 2006, 666). Indeed, John demonstrates heightened memory skills together with both enhanced auditory skills and oral language abilities- two features which Cooper $(1996,7)$ and Nikolic advise teaching staff to make full use of:

'The visually handicapped often display a marked talent for learning foreign languages. This seems to be the result of a particular aural sensitivity and the memory training which forms part of the rehabilitation process. Experience shows that [these] children [...] achieve excellent results in learning foreign languages, especially during the oral stage' $(1986,220)$.

Before coming to the University of Northampton, John attended a secondary school where specialist teachers catered for his additional needs. Hence, understandably, his expectations that his HE tutors would be au fait with teaching non-sighted students. Initially, John's unmet expectations inevitably engendered some degree of dissatisfaction and frustration on his part.

\section{Implementing 'inclusion strategies' Differentiated support}

The learning support assistant (LSA)

Students with additional needs are entitled to Disabled Students' Allowances (DSAs). These allowances assist the students in question with the additional disability-related costs directly connected with their studies. The DSAs may include financial help towards the additional expenses of travelling to the HEI concerned, a general allowance, a specialist equipment allowance, as well as a non-medical personal helper's allowance.

In John's case, the French course leader and the Access Ability Team agreed that an ex-student of French, Beth (not her real name), would be his learning support assistant. Beth had been awarded an upper second-class honours degree in French and English the previous year and was selected by the French tutors for her level of French, her personality and maturity. As Hodgson and Lewin-Jones 
contend, 'the support is more effective if the LSW speaks the target language. This applies both in the teaching sessions and outside the sessions. The VI students have to be in charge of their own independent study outside the taught sessions, and the LSW can be useful in enabling this' (2007). However, Hodgson and Lewin-Jones also warn MFL tutors: 'the emphasis has to be on independence here, or else the VI student ends up having additional tuition that goes beyond what the other students can access' (2007). The aforementioned authors further explain that 'there is a temptation for the LSW to over-intervene and correct errors, for example, in homework tasks' (2007)- hence the French course leader's decision to arrange a meeting at the very beginning of term one, during which the LSW's role and remit were clearly explained to Beth and John.

Beth and John immediately got on well; sadly, not everything was as positive as her working relationship with him:

'The amount of training I've received has been almost nil. The Access Ability Team [supplied me] with a booklet 'What Barriers' but that is very general. They also gave me a booklet from the Royal National College for the Blind [RNCB] called 'Sighted Guide Technique' but by the time I got that, I'd worked out with [John] how he wished me to help him move around campus. [...]

The staff meetings I've been to are mostly concerned with facilitators who take notes for people, which of course I rarely do for [John]. I suppose that meeting someone either from the RNCB or someone else who was blind, who could explain to me what a blind student needs that other students take for granted, would have been one good aspect. Also, I should mention the problems we had with Jaws, before we established a way of using it. I could have done with some idea of how it works' (2008).

Beth is referring to the high number of formally assessed online (translation, reading and listening comprehension as well as grammar) activities that students must complete (1) on a weekly basis as formative assessment and (2) as part of summative assessment. The weekly consolidation tasks (60 per module per year on average) have been designed by the French course leader with a quiz authoring programme called Hot Potatoes, which is freely available to educational institutions. As the latter software is not compatible with John's assistive software, Beth's main task was to help John complete, like his sighted peers, his weekly online activities by putting the mouse cursor in each of the appropriate blanks. John could then, like his sighted peers, type in his own answers. Let us not forget that the literature has highlighted (1) that Information Communications Technology (ICT) is a potentially important tool for the promotion of independent learning- since it enables learners to increasingly take over responsibility for their own learning (General Teaching Council for England, 2007) and (2) "how effective technology can greatly enhance the experience of the disabled students" (Orsini-Jones, 2009, 31).

\section{John's sighted fellow-learners}

As a supportive, enabling, and inclusive $\mathrm{T} / \mathrm{L}$ environment can only be fostered if all the VI student's sighted peers in the cohort in question adapt accordingly, both French tutors sought to generate an atmosphere conducive to better understanding and acceptance of other learners' differences. Both French tutors asked John's peers to always speak articulately, to answer one at a time and only once their own name had been called out by the French tutor so that John may hear everything that was being said, without having to rely on Beth to repeat what had just been said. 


\section{John's French tutors}

Both lecturers had to make reasonable adjustments to their respective teaching style and repertoire. They spelt out unfamiliar or complex terms and they (or John's sighted peers) read aloud everything that was being written on, or projected onto, the white board. They (or John's sighted peers) also gave a detailed description of any visual aids being used- such as pictures, tables, graphs, pie charts, etc. These easy-to-implement adjustments enabled John to follow, and fully participate in, all his French sessions; he was able, like his sighted peers, to fully engage with the T/L materials used during the lessons. One should emphasize that 'this approach of receiving input both visually and aurally is highly beneficial to all students, as it helps those whose preferred learning strategy is an aural one' (Lewin-Jones and Hodgson, 2004, 34).

Both French tutors also rearranged the seating plan on a regular basis so that John may work with several of his sighted peers. Indeed, 'the concern here has to be to avoid the isolation of the student. There may be a tendency towards over-reliance on the LSW, who can become an [...] electric fence if they are always working with the student and preventing others from doing so' (Hodgson and Lewin-Jones, 2007). This simple change made a significant difference and ensured inclusiveness.

Last but not least, John's French tutors very quickly realised that the most valuable source of information is John himself: he is the "expert" (Orsini-Jones, 2009, 30) - he knows how he learns best. Hence several meetings being arranged with John, Beth and the French course leader. The latter fully concurs with Hodgson and Lewin-Jones who state that 'the student's learning preferences have to be reviewed and understood before any modifications are made to the assessment pattern' (2007).

\section{Differentiation by resource Email attachments}

The French course leader decided in 2004 that (1) every French assignment would be made available on, and should be downloaded from, the University's Virtual Learning Environment (VLE) and (2) students would submit all their written assignments as email attachments. It was also decided that all written class activities would be concurrently typed by a student, then saved as a Word document on the French tutor's memory stick. Within 24 hours, the latter member of staff would electronically send the meaningfully-labelled file (such as 'FRE2005-France-contemporaineexercise1-page-16-22-may-2009') to the relevant cohort. It should be noted that these files benefit all sighted learners; the latter can fully concentrate on, and fully engage in, their class activities instead of taking (rarely error-free) notes. As for John, receiving an electronic, Jaws compatible version of all the activities completed in class enables him to revisit, on his own, the tasks that he needs to, whenever he wishes to. This very 'reasonable adjustment' enables him to be self-reliant.

\section{Qwizdom and WimbaCreate}

In MFL, because students' frequent exposure to written texts is central to the development of their accuracy, many valuable, traditional, 'sighted' activities are therefore used in class. Hence, the French course leader had to design several alternative activities with a view to not increasing John's dependency on sighted individuals. Some tasks were designed with WimbaCreate (a Microsoft Word add-on for converting Word documents into accessible web pages), others with Qwizdom (a 
user-friendly handheld electronic voting system, whose radio frequency handsets have numeric keys easy to distinguish by touch).

Thanks to the latter electronic voting system, an extremely valuable written task ("spot the grammar and spelling mistakes') was converted into a listening comprehension activity. Since 'recorded texts or dialogues may not address orthography, [and that] audio formats should therefore be supplemented with activities that address this' (Hamilton et al., 2006), the French course leader asked her students to listen to five sentences recorded by native speakers: one in English, followed by four possible translations in French. In each of the four latter possibilities, one of the words had been spelt out letter by letter and only one of these four words was accurate (Appendix, image 1).

Students had to use the numeric keypad of their Qwizdom handset to indicate their answers. This 'Who wants to be a millionaire?' style quiz enabled all students, whether VI or not, to participate on an equal footing. It did enable John to impress all his sighted peers- indeed, "listening [...] tasks do not normally present [...] blind students with any major problems" (Orsini-Jones, 2009, 30). Conversely, the latter students found the exercise very useful but considerably more challenging than when offered visual clues. This non-discriminatory activity undoubtedly enabled John's sighted fellow-students to gain a better understanding of the challenges faced by a non-sighted student, and, ultimately, to empathise with him.

Another valuable, formally assessed task that all year two students must complete is a web project which requires designing a website about a well-known French-speaking individual. Once again, an alternative, Jaws-compatible tool had to be found to enable John to design a website on his own. The French team heeded the advice of the Head of Learning Technology and Media and therefore opted for WimbaCreate. As the latter web authoring tool is very user-friendly (John could use it on his own after a mere 20-minute training session with the Head of Learning Technology and Media), John's sighted peers were asked to use it as well (a training session, tailor-made to the French tutors' requirements, was provided). In terms of design, functionality, and navigation, the quality of students' websites is noticeably better than prior to the introduction of WimbaCreate because the latter automatically generates a left hand menu with a list of hyperlinked headings (Appendix, images 2 and 3).

As explained above, the French tutors had to search for, and use, a Jaws compatible T/L tool because of John's impairment, but the user-friendliness of this Microsoft Word add-on proved beneficial to all learners. It is worth noting, as Orsini-Jones, Courtney, and Dickinson so rightly observed, that 'creating accessible web pages benefits all students, not just the disabled ones' (2005, 149).

\section{Differentiation by task Formal assessment}

As, without adjustments to (some of the French) formal assignments, 'it is inevitable that the disabilities of disabled students would be measured, not their academic achievements' (Konur, 2002, 131), formal assessment constitutes another area which the French tutors had to look into.

As Orsini-Jones, Courtney, and Dickinson aptly pointed out (2005, 149), a non-sighted student takes at least twice as long as his/her sighted peers to complete computer-based assessment (CBA). Consequently, John qualified for some extended time; he completed all his CBAs in a separate, suitably equipped room so that the sound made by Jaws and/or by Beth talking to John and acting as an invigilator may not disturb his sighted peers. 
As for marking, when reading John's first written assignment in French, because his tutors were unable to assess whether (some of) his linguistic errors stemmed from the limitations of his onscreen reader or from his own carelessness, they had to seek advice. Because of the unavailability of appropriate in-house expertise on Jaws, the French course leader arranged a meeting with a trainer from a local company supplying equipment to, and training, VI as well as non-sighted individuals. Knowing about Jaws' main functionalities prompted John's tutors to decide that the relevant currently-used marking schemes did not need to be altered for John. Differential marking was not introduced because, like any of his sighted peers, John could use his software's inbuilt spell checker. As Lewin-Jones and Hodgson aptly warn tutors, 'the issue of quality is crucial' (2007)- a note of caution already sounded in 2006 by Hamilton et al.: tutors 'should hold the same high standards for blind students as he or she would for all of the students in the class'. Academic standards should not be diluted.

\section{Returning assignments and providing feedback and feed forward}

As Meyer, Haywood, Sachdev and Faraday aptly note, it is 'important for teachers to provide pupils with adequate feedback on their homework since this improves pupils' confidence in working independently and may allow pupils to develop the reflective aspect of independent learning' (2008). They further explain that adequate feedback is 'important for independent learning because it allows pupils to understand the standard of performance expected of them, to monitor their own performance, and to know what they can do to improve' (2008).

Until John's enrolment, French assignments had always been returned with a paper cover sheet providing students with (1) marking criteria and (2) an extensive list of positive comments as well as task-specific action points; tutors would circle/tick each of the relevant pieces of information. However, as the latter cover sheets were not Jaws compliant, the French course leader had to find an alternative. The Northampton Business School's e-Learning Development and IT Support Manager provided her with a template that enabled her to create many task-specific questionnairestyle cover sheets.

Tutors must tick all the relevant comments and advice for improvement, then click on the "submit" button (Appendix, images 4, 5 and 6). A Jaws-compliant email containing all the carefully ticked comments/suggestions is automatically generated (Appendix, image 7) and sent to the relevant marking tutor- who forwards a copy to the appropriate student. As a result of this 'reasonable adjustment', John can, like any of his sighted fellow-students and whenever necessary, access his tutors' comments and suggestions for improvement. This enables him to reflect upon his tutors' advice and take charge of his own learning, ie be even more independent as a language learner.

\section{Conclusions and recommendations}

Orsini-Jones warns tutors that 'there [...] exists a certain tension between the reasonable anticipatory adjustments that lecturers can put into place and the necessary ad hoc ones that will be needed for a disabled student with very specific needs' $(2009,25)$. Tension will be even greater, and creating an inclusive T/L atmosphere even more difficult (if not impossible) if all stakeholders (academic, administrative, technical and support staff, but also disabled as well as non-disabled students) do not embark on a "collaborating learning journey" Orsini-Jones, 2009, 25). A 'can do' approach must be adopted- and fostered- by all. 
Hence, almost three years after the beginning of their challenging T/L journey, here is the French tutors' list of recommendations:

- tutors should enlist sighted learners as partners in the T/L process so as to 'maximize VI students' opportunities to interact with other [sighted] students' (Penman and Ricci, 2009), thereby promoting inclusion;

- tutors should listen to the SEN student's voice (Lewin-Jones and Hodgson, 2004, 36);

- tutors should 'be aware of overcompensating for the VI student to the detriment of the remaining students' (Lewin-Jones and Hodgson, 2004, 35);

- 'staff teaching [non-sighted students] should be given extra time for the preparation of both classes and tests/exams' (Orsini-Jones, Courtney, and Dickinson, 2005, 149);

- appropriate training should be offered to both staff and LSAs and

- as 'in terms of teaching foreign languages to learners with SEN, there is often little sharing of experience of good practice, [...] within many [European] member states' (Stevens and Marsh, 2005, 111) and as the same applies to UK HEIs ((Penman and Ricci, 2009), the launch of a free digital TV channel (similar to Teachers TV) would be timely; the channel would have its own dedicated website with video clips of practitioners' examples of good $\mathrm{T} / \mathrm{L}$ practice.

The European Language Portfolio for the Blind and Visually Impaired (ELPBVI) should very soon provide MFL tutors with much needed information on (1) 'the specific needs of the blind and visually impaired learners' aged 16 onwards (Schneider , 2008) as well as (2) suitable T/L approaches (for example 'non-visual learning methods' (Schneider , 2008)).

Needless to say that it has been a steep learning curve for the French tutors concerned. However, two points are worth noting:

(1) without the ad hoc, sometimes time-consuming, 'reasonable adjustments' implemented, John's T/L environment could not have been as supportive, enabling, and inclusive and his independent learning skills could not have been fostered/ further developed- and he would not have passed French.

(2) thanks to John's specific additional needs, the French tutors had to 'think outside the box'. Hence, they fully agree with Lewin-Jones and Hodgson's conclusion: 'developing differentiation strategies for including students with severe VI has led to our tutors reflecting on their teaching styles, which has been [...] challenging [but also] stimulating' (2007)- and beneficial to all students, whether sighted or not. The French tutors therefore concur with McEwan, Cairncross and MacLean who, already in 2003, stated that 'what initially appears to require a radical rethink in our approach actually only requires a commitment to emerging best practice' (1).

\section{References}

Beth [pseud.]. (2008) Email exchange. Northampton

Bolt, D. (2004) Disability and the rhetoric of inclusive higher education. Journal of Further \& Higher Education 28, (4): 353-8. 
Carrington-Porter, D., Patton, B. and Roy, A.W.N. (1994) Visually handicapped students in higher education: the position in Eastern Europe. European Journal of Special Needs Education 9, (1): 4051.

Cooper, H. (1996) Teaching modern languages to visually impaired children. Language Learning Journal 13: 6-9

Dickinson, A. (2005) Don't panic (smile)! How visually impaired students access online learning and giving realistic guidelines to academic staff at Coventry University. International Congress Series 1282: 836-40.

European Agency for Development in Special Needs Education. (2006) Special needs education in Europe - (Volume 2) - Provision in post-primary education

http://www.european-agency.org/site/info/publications/agency/ereports/docs/18docs/Thematic-

EN.pdf

General Teaching Council for England. (2007) Transforming teaching and learning with ICT. www.gtce.org.uk/research/romtopics/rom_teachingandlearning/ict_nov07/study

Hamilton, E., Prime, K., Gilson, G., Caron, E., Rathlef, J. and Fischer, H. (2006) Students who are blind or visually impaired accessing foreign languages. Mobility International USA, http://www.miusa.org/ncde/tipsheets/foreignlang/

HESA. (1997) First Year UK-domiciled HE Students by level of course, mode of study, gender, and disability 1996/97

http://www.hesa.ac.uk/dox/dataTables/studentsAndQualifiers/download/disab9697.csv

HESA. (2005) Table $11 \mathrm{~b}$ - First year UK-domiciled HE students by qualification aim, mode of $\begin{array}{llll}\text { study, } \quad \text { gender disability } & \text { and }\end{array}$ http://www.hesa.ac.uk/dox/dataTables/studentsAndQualifiers/download/disab0405.xls

HESA. (2007) Table 11 - First Year UK-domiciled HE Students by qualification aim, mode of study, gender and disability 2006/07

http://www.hesa.ac.uk/dox/dataTables/studentsAndQualifiers/download/disab0607.xls

Lewin-Jones, J., and Hodgson, J. (2004) Differentiation strategies relating to the inclusion of a student with a severe visual impairment in higher education (modern foreign languages). The British Journal of Visual Impairment 22, (1): 32-6.

Hodgson, J. and Lewin-Jones, J. (2007) Differentiation strategies for the inclusion of students with severe visual impairment in MFL modules in Higher Education, Subject Centre for Languages, Linguistics and Area Studies, http://www.llas.ac.uk/resources/paper/2724

Holec, H. (1981) Autonomy and Foreign Language Learning. Oxford: Pergamon Press.

Klinkosz, W., Sekowski, A. and Brambring, M. (2006) Academic achievement and personality in university students who are visually impaired. Journal of Visual Impairment \& Blindness 100, (11): 666-75. 
Konur, O. (2002) Assessment of disabled students in higher education: current public policy issues. Assessment \& Evaluation in Higher Education 27, (2): 131-52.

McEwan, T. Cairncross, S. and MacLean, A. (2003) Good practice for disabled students is good practice for all. Napier Staff Conference: Engaging our Students http://www.ed.napier.ac.uk/staffconference/june2003/papers/mcewan.pdf

Meyer, B. Haywood, N., Sachdev, D. and Faraday, S. (2008) Independent Learning -Literature Review, Research Report DCSF-RR051, Learning and Skills Network, http://www.dcsf.gov.uk/research/data/uploadfiles/DCSF-RR051.pdf

Nikolic, T. (1986) Teaching a foreign language to visually impaired children in school. Language Teaching 19, (3): 218-31

Orsini-Jones, M., Courtney. C. and Dickinson, A. (2005) Supporting foreign language learning for a blind student: a case study from Coventry University. Support for Learning 20, (3): 146-52.

Orsini-Jones, M. (2009) Visual impairment in Higher Education - Measures for inclusion: coping with the challenge of visual impairment and blindness in university undergraduate level language learning, Support for Learning - British Journal of Learning Support 24 (1): 27-34.

Penman, C., Ricci, Julie. (2009) Reflections on the experience of a visually-impaired learner of French, Edinburgh Napier University Staff Conference: Enabling our Students to Become Effective Learners http://www2.napier.ac.uk/ed/staffconference/june2009/poster/penman.ppt

Pumfrey, P. ( 2008) Moving towards inclusion? The first-degree results of students with and without disabilities in Higher Education in the UK: 1998-2005. European Journal of Special Needs Education 23, (1): 31-46.

Richardson, J. and Roy, A. (2002) The representation and attainment of students with a visual impairment in higher education. British Journal of Visual Impairment 20, (1): 37-48.

Schneider, C. (2008) Interview. Elpforblind.eu http://elpforblind.eu//admin/uploaded/Interview_Christel_Schneider_EN_5.doc

Stevens, A. and Marsh, D. (2005) Foreign language teaching within special needs education: learning from Europe-wide experience. Support for Learning 20, (3): 109-14.

The English Collins Dictionary - English Definition \& Thesaurus (2000) http://dictionary.reverso.net/english-definitions/

The University of Northampton. (2008) Student services: the Access Ability Team. http://www.northampton.ac.uk/departments/studentservices/access-ability/

Wenden, A. (1991) Learner strategies for learner autonomy. London: Prentice Hall. 


\section{About the author}

Géraldine Enjelvin is Senior Lecturer in French in Northampton Business School at the University of Northampton.

Email: geraldine.enjelvin@ northampton.ac.uk

\section{Appendix}

\section{1. we are pleased you are interested in our very latest products}
A) nous sommes heureux de votre intérêt dans vos nouveaux produits
B) nous sommes heureux de votre intérêt que vous portez à tous nos nouveaux produits
C) nous sommes heureux de l'intérêt que vous portez à nos tout nouveaux produits
D) nous sommes contents de l'intérêt que vous portez à nos tout nouveaux produits

\section{Image 1: activity designed for Qwizdom}

\section{Daniel Balavoine}

\section{Table des matières}

1. Les raisons de mon choix

2. Les points importants de sa biographie

3. Ses traits de caractère

4. Ce que disent les médias : en bien

5. Ce que disent les média : en mal

6. Comparaison avec une personnalité britannique

7. Références

\section{Les raisons de mon choix}

J'adore cette célébrité parce que :

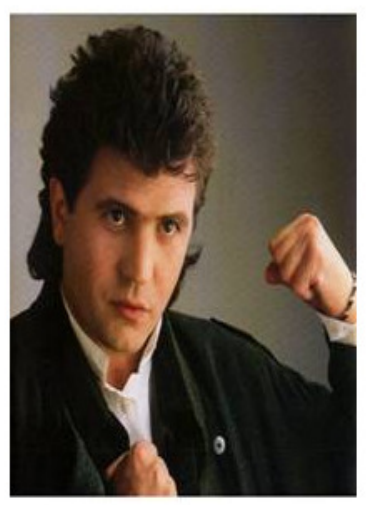

Source : http://www.images.google.co.uk

Image 2: web project designed with WimbaCreate (a) 


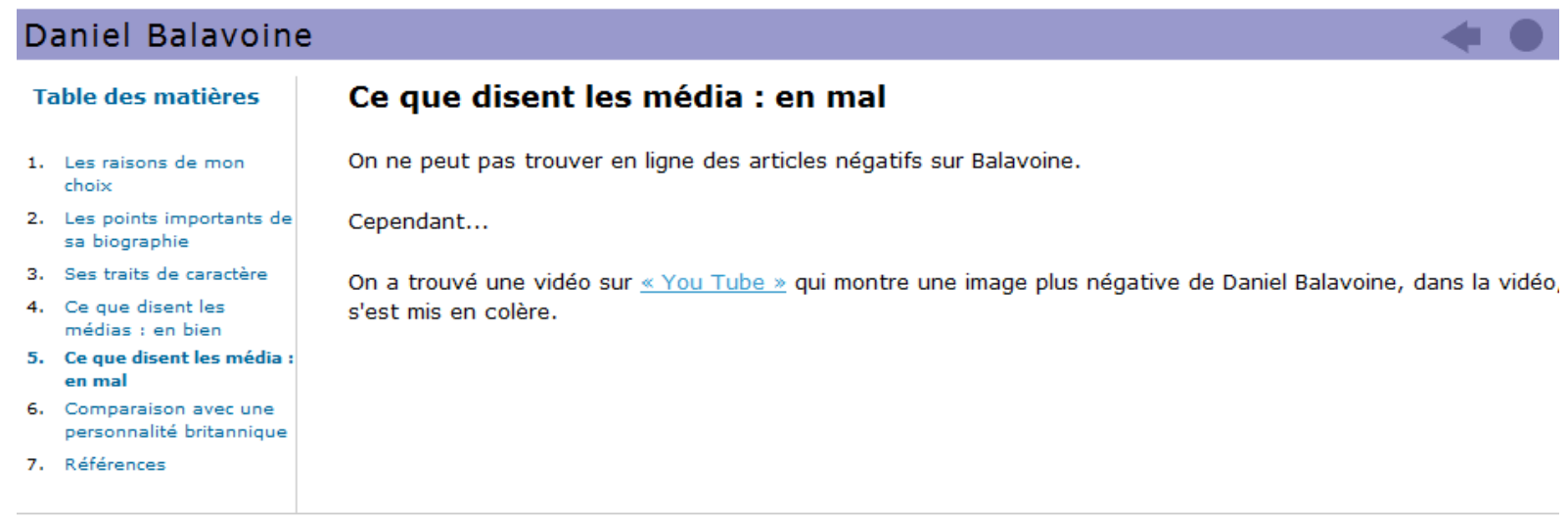

Site internet créé avec WimbaCreate

Image 3: web project designed with WimbaCreate (b)

|FRE2001 assignment 2 - feedback \& feed forward

\begin{tabular}{|c|c|}
\hline Name: & $\mathrm{J} / \mathrm{m}$ \\
\hline Assignment: & FFE2001 assignment 2 - feeoback \\
\hline Overall grade & $\mathrm{B}+$ (Part one: $\mathrm{B}+$; Part wo: $\mathrm{Ct}$ ) \\
\hline Preferred email address: & French that Q Qnorthampton ac ux \\
\hline
\end{tabular}

* Required field

Part 1: Commentary in French:

\section{Content quality}

$r$ Excellent.

$r$ Very good.

$r$ Good.

$r$ Some flaws

$r$ Serious flaws.

r Clear fail.

Image 4: questionnaire-style feedback to students (a) 
Part 1: Commentary in French:

\section{Language quality}

\begin{aligned} &$r$ Excellent. \\ &$r$ Very good. \\ &$r$ Good. \\ &$r$ Some flaws. \\ &$r$ Serious flaws. \\ &$r$ Clear fail. \\ & \hline\end{aligned}

Advice on language, Check

$\ulcorner$ Vocabulary is appropriate; use a dictionary.

$\ulcorner$ Register; too informal at times.

$\ulcorner$ Spelling; use a dictionary or spell checker.

$\ulcorner$ Word order,

Image 5: questionnaire-style feedback to students (b)

\section{TAdvice on language. Revise other.}

$\Gamma$ Gender.

$\Gamma$ Verb with preposition such as, in French, de, a with a grave accent;

$\Gamma$ Passive voice.

$\Gamma$ Direct pronouns such as, in French, le, la, les.

$\Gamma$ Indirect pronouns such as, in French, lui. leur.

\section{Part 2: Online tasks}

\section{Quality}

\section{r Excellent.}

Very good.

$r$ Good.

C Some flaws.

$r$ Serious flaws.

r. Clear fail.

r Some tasks not completed.

Submi

Image 6: questionnaire-style feedback to students (c) 


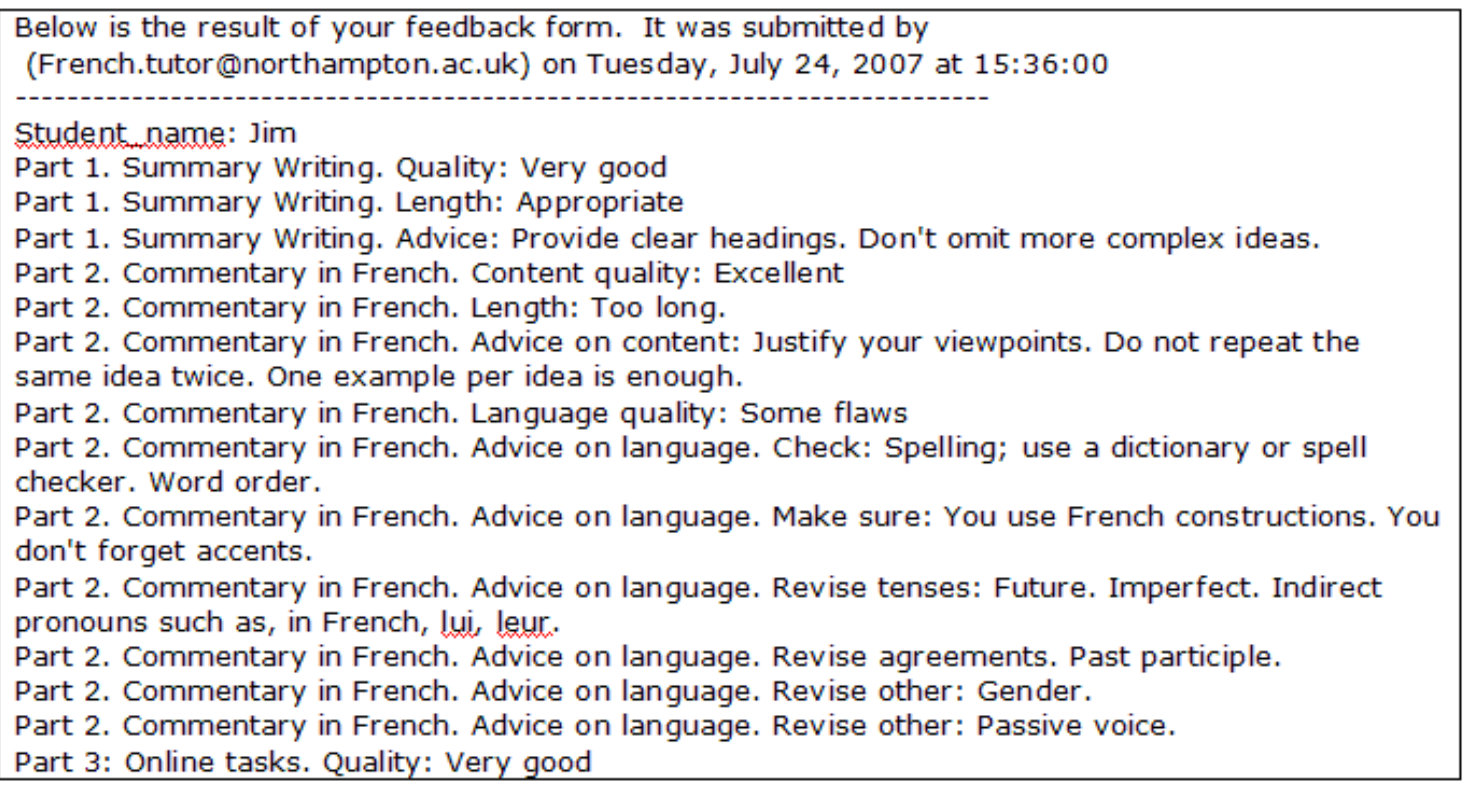

Image 7: JAWS-compliant email generated by feedback/feed forward form 